\title{
Level of Effect of the Training Courses on Improving the Occupational Performance of the Teachers in Zarqa from the Teachers' Perspectives
}

\author{
Zohair Al Zoubi' ${ }^{1}$ Mahmoud Hatamleh ${ }^{2}$ \\ ${ }^{1}$ Faculty of Educational Sciences, The Hashemite University, Zarqa, Jordan \\ ${ }^{2}$ Faculty of Physical Education and Sport Sciences, The Hashemite University, Zarqa, Jordan \\ Email: mahoud_1969@yahoo.com
}

Received 17 March 2016; accepted 14 May 2016; published 17 May 2016

Copyright (C) 2016 by authors and Scientific Research Publishing Inc.

This work is licensed under the Creative Commons Attribution International License (CC BY). http://creativecommons.org/licenses/by/4.0/

\section{(c) (i) Open Access}

\begin{abstract}
This study aimed at identifying level of effect of the training courses on improving the occupational performance of the teachers in Zarqa from the Teachers' perspectives. The variables of study are gender, specialization, academic degree, years of experience and training courses. The study employed the descriptive survey method and depended on the questionnaire for data collection. The sample of study, consisted of $\mathbf{4 5 0}$ teachers of the education directorates in Zarqa, was chosen by random method in academic year 2014/2015. The result of study revealed no statistically significant differences between variables of study gender, specialization, academic degree, years of experience, and training courses. The study recommended the evaluation of the training courses. The study recommended exploring the reasons for dereliction in performing the duties assigned to the male and female teachers to treat them and avoid such reasons in the future. The study also recommended paying attention to the quality requirement in education, and the literature, concepts and methods of application and improvement.
\end{abstract}

\section{Keywords}

Training Courses, Occupational Performance, Teachers

\section{Introduction}

Human resources issues are given great attention by writers and researchers in this area because of the signifi-

How to cite this paper: Al Zoubi, Z., \& Hatamleh, M. (2016). Level of Effect of the Training Courses on Improving the Occupational Performance of the Teachers in Zarqa from the Teachers' Perspectives. Advances in Physical Education, 6, 126-134. http://dx.doi.org/10.4236/ape.2016.62014 
cant role the human resources play in the organizations, which may contribute to the success or failure of the organizations. The excellence of the organizations' performance is related to the excellence of the workers in these organizations. Subsequently, organizations are required to maintain the sustainability of the excellence and efficiency of its human resources through the workers in training (Aqeeli, 2009).

Training has one of the most important foundations of work development because of its role in raising the efficiency of the workers, and providing them the skills to improve the performance of their works and upgrade the general level of the parties they work for. In this concern, the portion the employee learns from the theoretical aspect does not cover the developed requirements of many occupations. This is true because most jobs develop as a result of the quick development in technology, communications and the people's desires (Al-Ta'ani, 2007).

Training in the realm of the temporary communities and organizations is the development instrument and means; it is also the instrument, which will, if well invested and employed, be able to achieve the efficiency and sufficiency in performance and production. Training provides new knowledge, adds various information, gives skills and abilities, affects the trends, amends the thoughts, changes the behaviors, and develops the habits and methods at the work (Al-Sakarneh, 2009).

The training is the positive amendment process with special directions that deals with the individual's behavior both in the professional and occupational aspects to acquire the knowledge and experiences he needs. It is also important for the individual to achieve the information he lacks and the trends good for work, management, behavioral styles, and skills and habits required to raise efficiency level in performance and increase production (Reda, 2010).

Training is of very vital importance for the teachers and school leadership to serve the needs of the individuals and to success in the educational and administrative process (Al-Husni, 2011; Al-Shar'ah, 2011). And training helps teacher to gain new and skills, acquire positive trends toward the profession, and gain the ongoing learning methods to achieve the planned objectives (Mi'mar, 2010; Al-Khatib \& Al-Anzi, 2008; Al-Ta'ani, 2007). The training process is subject to many general principles, which should be observed throughout all the stages of this process as set forth by Al-Sairafi (2009).

The training process included the teacher, who is one of the factors leading to the success of training, which is the existence of a trainee who is convinced to the training objectives and need to such training; as the trainee is the basis and focus of the training process. The trainer is the person responsible for preparing and selecting the suitable scientific material. Therefore, it is important to select the suitable trainer, who is able to use the training method and its various styles. And the scientific material, which must be within the contents of the training kit, and is in the shape of a theoretical material or an applied practical aspect (Al-Qarni, 2015).

Training should be according to a well-studied and detailed plan, and applied through an accurate method, then evaluated for detecting the strengths and weaknesses with them. It is clear that training, to be successful, should contain the delicate definition of the training needs, being the base for the teachers' training success at schools (Mi'mar, 2010).

The world nowadays is witnessing competition and attention in the performance issue, and the effectiveness and efficiency of the organizations in performing their functions, and achieving the objectives for which they are initiated, requiring from all organizations a focus on the human element to achieve their goals through the effectiveness of the utilization of the resources, and taking up the available opportunities and energies to upgrade the human performance level, as well as the institutional performance of the organizations to provide services quickly and efficiently to secure its continuity, growth and development (Al-Kubaisi, 2010; Salameh, 2003).

The process of evaluating the performance requires describing the performance rates through defining the values related to the plans, upon which lights the achieved results would be measured. Therefore, the performance rate is a planning instrument expressing an end that is required to be approached. It may also reflect a plane, approach or method used to perform a certain activity. Without defining the performance rates and criteria, it is difficult to measure the performance and approach an accurate judgment on how efficient it is (AlKharousi, 2003). The individual performance level requires knowing the factors that define this level and the interaction between these factors. Because these factors are multiple, and because of the difficulty in determining the degree of effect of each on the performance, and due to the differences in the previous studies results, researchers are facing many difficulties in defining the factors affecting performance and the interaction extent between them (Jadallah, 2010). 
In general, we can summarize the factors affecting the occupational performance into two major groups. First, technical factors, which include technological advancement, raw materials, organizational structure of work, work methods and means. No doubt, the technical factors have their great and direct effect on the organization efficiency as well as on its individuals. As such, the type of equipment, raw materials, methods and styles of work, process design all affect the level of the organization productivity level. Second, human factors, which include ability to actually perform work, define the know-how, training, education, experience, skill and personal ability. It also includes eagerness to work and defines the physical and social work conditions, as well as the needs and desires of the individuals (Al-Haddad, 2007; Mkhaimer, 2000; Al-Salami, 2012).

Studies outlined the importance of the training programs to the occupational performance (Al-Anzi, 2010; Barnett, 2005; Jones, Jones, Latreille and Sloane, Khan, 2009; Manasa \& Reddy, 2009, Chang \& Quang, 2011; Falola, Osibanjo \& Ojo, 2014; Ajibade \& Ayinla, 2014; Khattak, Rehman \& Abdul Rehman, 2014), and indicated that there was a positive effect of the training programs and courses on the improvement of the individuals' performance, whether they were teachers or other workers at the different sectors. This, in turn, will positively reflect on the productivity and the organizational commitment levels of these individuals.

The researcher noticed that there was difference between the teachers, who joined management-training courses, in the level of their performance in the field of their work. This made the researcher think of the topic of this study, which could be defined to identify the effect of the training courses in improving the teachers' performance in the ministry of education, as viewed by the teachers in the education directorates in Zarqa.

\subsection{Objectives}

The study aimed at identifying the effect of the training courses on the improvement of the teachers' performance in Zarqa.

\subsection{Questioners}

1) What is the level of the training courses provided to the teachers in Zarqa, as viewed by the teachers themselves?

2) What is the level of the teachers' performance in Zarqa, as viewed by the school principals?

3) Are there significant differences at $(\alpha \leq 0.05)$ level for the training courses in improving the teachers' performance in Zarqa, as viewed by the teachers themselves that are attributed to "gender, specialization, academic qualification, years of experience, and training courses?

\section{Methodology}

\subsection{Study Sample}

Study sample was chosen by the simple random way; the sample consisted of (450) male and female teachers (230 male and 220 female teachers). Table 1 indicates the distribution of the study sample over the study variables.

\subsection{Instrument}

The study used the tool, which was developed depending on the previous studies and events that were explored. First part included the variables: gender, specialization, academic qualification, years of experience, and training courses. The second part consisted of two sections.

1) Training Programs, contained (41) items distributed over four domains as follows:

a) Identifying the training needs ( 7 items)

b) Designing the training program (13 items)

c) Implementing the training program (11 items), and

d) Evaluating the training program (10 items.

2) Occupational Performance, contained (37) items distributed over three domains as follows:

a) Performance speed (13) items

b) Performance efficiency (13) items.

c) Skills (11) items. 
Table 1. Distribution of the study sample over its variables.

\begin{tabular}{|c|c|c|c|}
\hline Variable & Category & Frequencies & $\%$ \\
\hline \multirow{2}{*}{ Gender } & Male & 230 & $51 \%$ \\
\hline & Female & 220 & $49 \%$ \\
\hline \multirow{2}{*}{ Specialization } & Scientific & 190 & $42 \%$ \\
\hline & Literary & 260 & $58 \%$ \\
\hline \multirow{3}{*}{ Academic Qualification } & BA & 290 & $64 \%$ \\
\hline & MA & 120 & $27 \%$ \\
\hline & Ph.D & 40 & $9 \%$ \\
\hline \multirow{3}{*}{ Years of Experience } & Less than $5 \mathrm{y}$ & 110 & $24 \%$ \\
\hline & $5-10 y$ & 120 & $27 \%$ \\
\hline & $11 \mathrm{y}$ and more & 220 & $49 \%$ \\
\hline \multirow{3}{*}{ Training Courses } & One Course & 220 & $49 \%$ \\
\hline & Two Courses & 180 & $40 \%$ \\
\hline & Three Courses & 50 & $11 \%$ \\
\hline Total & & 450 & $100 \%$ \\
\hline
\end{tabular}

\subsection{Validity and Reliability}

To verify the validity of the instrument, it had been presented to a number of experienced and specialized professors of the Hashemite University, to make their views and remarks on the validity of its items and domains, in terms of the scientific accuracy, wording, meanings and degree of its suitability to the study field and topic. Following to obtaining the opinions of the arbitrators, all their remarks received were taken into consideration.

The research included the item that gained the agreement of (10) arbitrators or more, i.e. (80\% and more) of the arbitrators. Moreover, the researcher took into account their remarks concerning the deletion, amendment of wording as well as adding new proposed items and discarding the items that did not receive agreement of the arbitrators. Accordingly, the final number of the items settled on (78) items, distributed over two sections. They were given a graded weight, according to Liker's five-point scale, as follows: Excellent (5) points, Very Good (4) points), Good (3) points, Satisfactory (2) points, and Poor (1) point.

The test-retest techniques, and the instrument was distributed over an initial sample of (20) male and female teachers through two week, were corrected and degrees were obtained, in addition to obtaining the relationship between the first and second examinations, using Pearson Correlation Coefficient, which was (0.89), i.e. a statistically significant correlation coefficient. Furthermore, the internal consistency coefficient (Cronbach Alpha) was obtained for the study instrument with its two sections and domains, as shown in Table 2.

\subsection{Study Procedures}

The study started after fulfilling the conditions: in terms of preparing the study instrument, verification of its validity and reliability. The researchers determined the study population and sample, and obtained the official approvals of the Ministry of Education to carry out the study, and to facilitate the researchers' assignment to distribute the questionnaire over the study sample from $1 / 2 / 2015$ to $15 / 3 / 2015$. The researchers clarified to the study population that their responses will be for the purposes of the scientific research only, so as to achieve objectivity. After collecting the questionnaires, the researchers accumulated them, assorted them, posted the responses, entered the data into the computer, analyzed them and obtained the results according to the study questions.

\subsection{Statistical Methods}

The researchers used in the statistical processing: means and standard deviations and percentages and T-test and 
Table 2. Reliability coefficients according to Cronbach alpha and test-retest methods of the study instruments with its two sections and domains.

\begin{tabular}{ccc}
\hline Domain & Internal Consistency (Cronbach Alpha) & Test and Retest \\
\hline Defining the Training Needs & 0.94 & 0.89 \\
Training Course Design & 0.90 & 0.87 \\
Training Course Implementation & 0.91 & 0.84 \\
Training Course Evaluation & 0.92 & 0.86 \\
Total Training Programs & 0.98 & 0.89 \\
Performance Speed & 0.90 & 0.90 \\
Performance Efficiency & 0.94 & 0.88 \\
Skills & 0.92 & 0.90 \\
Total & 0.94 & 0.88 \\
\hline
\end{tabular}

the ANOVA test to obtain the study results.

\section{Results and Discussion}

The first Question: What is the level of the training courses provided to the teachers in Zarqa, as viewed by the teachers themselves? To answering this question, the M's and SD's concerning the responses of the study sample to the study question were calculated. Later, results of the first question will be displayed. Table 3 illustrates the M's and SD's of the study domains.

Table 3 which concerns the different training programs domains, indicates that the order of the domains, according to the mean (M), were as follows: Training needs in the first rank with (3.38) mean; training program design second with (3.11) mean; training program implementation third with (3.05) mean; and training program evaluation was the fourth and last with (2.76) mean. On the other hand, the overall level of the training programs of the domains was medium with (3.08) mean.

This study is in line with the results of the following studies: Al-Anzi (2010); Barnett (2005); Jones, Jones, Latreille, \& Sloane, 2009); Manasa \& Reddy (2009); Chang and Quang (2011); Khan, Ajibade, \& Ayinla (2014); Falola, Osibanjo, \& Ojo (2014), Khattak, Rehman, \& Abdul Rehman (2014). All these studies indicated the existence of a positive effect of the programs and training courses on improving the performance of the individuals, whether they were teachers or workers in the different sectors.

The second Question: What is the level of the teachers' performance in Zarqa, as viewed by the school principals? Table 4 indicates the M's and SD's of the study domains.

Table 4 of the domains of the occupational performance indicates that the order of the occupational performance by the mean was as follows: skills in the first rank with (3.76) mean, performance efficiency in the second with (3.06) mean, and the performance speed came third and last with (2.76) mean. The overall level of the domains of the occupational performance was medium with (3.25) mean.

This study is in line with the results of the following studies: Al-Anzi (2010); Barnett (2005); Jones et al. (2009); Manasa \& Reddy (2009); Chang and Quang (2011); Khan, et al. (2014); Falola et al. (2014) and Khattak et al. (2014). All these studies indicated the existence of a positive effect of the programs and training courses the workers take on the performance of the individuals, which is reflected in their productivity.

The third Question: There are no significant differences at $(\alpha \leq 0.05)$ level for the training courses in improving the teachers' performance in Zarqa, as viewed by the teachers themselves that are attributed to "gender, specialization, academic qualification, years of experience, and training courses (Tables 5-8).

The means and standard deviations, as well as the t-test results of the grades of the training courses programs level were obtained to show their effect on the improvement of the male and female teachers' performance, according to the gender. Table 5 indicates the results.

Results of T-test for testing the differences in the training courses programs, by gender, indicate that there are no statistically significant differences at $(\alpha \geq 0.05)$ level in the improvement of the occupational performance, with the male and female teachers in Zarqa, that are attributed to the gender variable, as $\mathrm{T}$ value amounted (1.01). 
Table 3. M's and SD's of the domains of the training programs on the domains as a whole.

\begin{tabular}{cccccc}
\hline No. & Domains & Rank & M & SD & Training Level \\
\hline 1 & Defining the Training Needs & 1 & 3.38 & 0.68 & Medium \\
2 & Training Program Design & 2 & 3.11 & 0.84 & Medium \\
3 & Training Program Implementation & 3 & 3.05 & 0.70 & Medium \\
4 & Training Program Evaluation & 4 & 2.76 & 0.87 & Medium \\
& Overall & & 3.08 & 0.80 & Medium \\
\hline
\end{tabular}

Table 4. M's and SD's of the domains of the occupational performance on the domains as a whole.

\begin{tabular}{cccccc}
\hline No. & Domains & Rank & M & SD & Training Level \\
\hline 1 & Performance Speed & 3 & 2.94 & 1.24 & Medium \\
2 & Performance Efficiency & 2 & 3.06 & 0.70 & Medium \\
3 & Skills & 1 & 3.76 & 0.80 & High \\
& Overall & & 3.25 & 0.75 & Medium \\
\hline
\end{tabular}

Table 5. M's, SD's, and T-test results to examine the effect of the differences in the training courses programs on improving the occupational performance, according gender variable.

\begin{tabular}{cccccccc}
\hline Domain & Gender & Sample & M & SD & T & Sig \\
\hline \multirow{2}{*}{ Gender } & Male & 230 & 3.8 & 0.62 & \multirow{2}{*}{1.01} & 0.317 \\
& Female & 220 & 3.5 & 0.52 & &
\end{tabular}

Table 6. M's, SD's, and T-test results to examine the effect of the differences in the training courses programs on improving the occupational performance, according to specialization variable.

\begin{tabular}{ccccccc}
\hline Domain & Gender & Sample & M & SD & T & Sig \\
\hline \multirow{2}{*}{ Specialization } & Scientific & 190 & 3.77 & 0.51 & \multirow{2}{*}{0.267} & 0.79 \\
& Humanities & 260 & 3.80 & 0.77 & & \\
\hline
\end{tabular}

Table 7. M's, SD's, and T-test results to examine the effect of the differences in the training courses programs on improving the occupational performance, according to academic qualification variable.

\begin{tabular}{cccc}
\hline Academic qualification & No. & M & SD \\
\hline BA & 290 & 3.71 & 0.60 \\
MA & 120 & 3.80 & 0.50 \\
Ph.D. & 40 & 3.80 & 0.68 \\
\hline
\end{tabular}

Table 8. Results of the analysis of variance (ANOVA) according to the academic degree.

\begin{tabular}{|c|c|c|c|c|c|}
\hline Source of Variance & Squares Total & Freedom Degree & Mean Total Squares & $\mathrm{F}$ & Sig \\
\hline Inter-Groups & 0.12 & 2 & 0.06 & \multirow{3}{*}{0.16} & \multirow{3}{*}{0.855} \\
\hline Intra-Groups & 28.85 & 447 & \multirow{2}{*}{0.39} & & \\
\hline Total & 28.97 & 449 & & & \\
\hline
\end{tabular}

The researchers obtained the M's, SD's and T-test results of the grades of the training courses programs level in improving the male and female teachers' performance according to specialization. Table 6 indicates the results.

Results of T-test for testing the differences in the training courses programs, by academic specialization variable, indicate that there are no statistically significant differences at ( $\alpha \geq 0.05$ ) level in the improvement of the occupational performance, with the male and female teachers in Zarqa, that are attributed to the academic spe- 
cialization variable, as $\mathrm{T}$ value amounted (0.267).

For identifying the differences among the responses of the study sample individuals, by the academic qualification, in the effect of the training courses programs on the occupational performance, the researchers calculated the M's, SD's, and then employed the analysis of variance procedure (ANOVA).

Table 7 of the academic degrees indicates the existence of apparent differences in the means. It amounted (3.71) for the male and female teachers who hold BA degree, and was (3.80) for both the MA and Ph.D. degrees holders.

The above table indicates that there are no statistically significant differences at $(\alpha \geq 0.05)$ level of the degree of the training courses programs attributed to the academic degree variable. F value amounted (0.16), which is statistically insignificant at the $(\alpha \geq 0.05)$ level.

Identifying the differences among the responses of the study sample individuals, by the years of experience, in the effect of the training courses programs on the occupational performance, the researchers calculated the M's, SD's, and then employed the analysis of variance procedure (ANOVA).

Table 9 showed apparent differences in these according to the years of experience means. They amounted (3.90) for teachers with less than 5 years of experience, (3.64) for teachers with experience from 6 to 10 years, and (3.82) for those having 11 years and more of experience. In order to text the significance of these differences, ANOVA values were obtained. Table 10 indicates these results.

Table 10 indicates that there are no statistically significant differences at $(\alpha \geq 0.05)$ level of the degree of the training courses programs attributed to the years of experience variable. F value amounted (1.03), which is statistically insignificant at the $(\alpha \geq 0.05)$ level.

For identifying the differences among the responses of the study sample individuals, by the number of training courses, in the effect of the training courses programs on the occupational performance, the researchers calculated the M's, SD's, and then employed the analysis of variance procedure (ANOVA).

The means in the above Table 11, according to the number of training courses, indicated apparent differences in these means. They amounted (3.83) for the teachers who took (one course); (3.73) for those who took (two courses) and (3.79) for those who took two courses and more. For testing the significance of these differences, ANOVA values were obtained. Table 12 Illustrates these results.

Table 9. M's and, SD's of the effect of the training courses programs on improving the occupational performance, according to the years of experience variable.

\begin{tabular}{cccc}
\hline Years of Experience & No. & M & SD \\
\hline Less than 5 years & 110 & 3.90 & 0.69 \\
From 5-10 years & 120 & 3.64 & 0.57 \\
Aa years and more & 220 & 3.82 & 0.61 \\
\hline
\end{tabular}

Table 10. Results of the analysis of variance (ANOVA) according to the years of experience.

\begin{tabular}{ccccc}
\hline Source of Variance & Squares Total & Freedom Degree & Mean of the Total Squares & F \\
\hline Inter-Groups & 0.79 & 2 & 0.39 & 1.03 \\
Intra-Groups & 28.19 & 447 & 0.36 \\
Total & 28.98 & 449 & & 0.38 \\
\hline
\end{tabular}

Table 11. M's and, SD's of the effect of the training courses programs on improving the occupational performance, according to the number of courses variable.

\begin{tabular}{cccc}
\hline Training Courses & Number & M & SD \\
\hline One Course & 220 & 3.83 & 0.68 \\
Two Courses & 180 & 3.73 & 0.70 \\
Three Courses and More & 50 & 3.79 & 0.44 \\
\hline
\end{tabular}


Table 12. The analysis of variance (ANOVA) according to the number of training courses.

\begin{tabular}{cccccc}
\hline Source of Variance & Squares Total & Freedom Degree & Mean of the Total Squares & F Value & Significance Level \\
\hline Inter-Groups & 0.15 & 2 & 0.077 & 0.198 & 0.82 \\
Intra-Groups & 28.82 & 447 & 0.389 & & \\
Total & 28.97 & 449 & & \\
\hline
\end{tabular}

The above table indicates that there are no statistically significant differences at $(\alpha \geq 0.05)$ level of the degree of the training courses programs attributed to the number of the training courses variable. F value amounts 0.198 , which is statistically insignificant at the $(\alpha \geq 0.05)$ level.

\section{Conclusion}

The conclusion was drawn on the basis of the study findings. There are no statistically significant differences between variables of study gender, specialization, academic degree, years of experience, and training courses.

\section{Recommendations}

Placing more importance to the evaluation of the training programs after applying them, to judge the degree of their quality, in terms of increasing both the theoretical and professional knowledge, for the purpose of identifying their effects on the workers

Reinforcing the training needs and identifying them more accurately to fit the wok requirements and contribute to the increase in performance.

Taking more care in the feedback of the evaluation process for the purpose of ongoing improvement and development of the service provided in approach to the excellence in performance.

\section{References}

Ajibade, S., \& Ayinla, N. (2014). Investigating the Effect of Training on Employees' Commitment: An Empirical Study of Discount House in Nigeria. Megartrend Review, 11, 7-18.

Al-Anzi, A. (2010). Training Needs of the Educational Leaders in the Ministry of Education in the State of Kuwait, as Viewed by Them. Faculty of Education Journal, Benha, 81, 126-183.

Al-Haddad, Z. H. (2007). Relationship between Communications and Occupational Performance. Unpublished MA Thesis. Amman: University of Jordan.

Al-Husni, I. (2011). Collaborative Training and Raising the Work Performance. Amman: Debono Center for Teaching Thinking.

Al-Kharousi, S. (2003). Effect of the Administrative Information Systems on the Public Directorates and Departments in Sahar Province, Sultanate of Oman, A Case Study. Unpublished MA Thesis. Mafraq: Al al-Bayt University.

Al-Khatib, A., \& Al-Anzi, A. (2008). Designing the Training Courses of the Educational Leaderships. Amman: Gadara International Book for Publication and Distribution.

Al-Kubaisi, A. (2010). Security Administrative Training: A Contemporary Vision of the $21^{\text {st }}$ Century. Riyadh: Studies and Research Center, Nayef Arab University for Security Studies.

Al-Qarni, A. (2015). Vocational Development Styles of the Public Schools’ Principals in the City of Riyadh (S.A.) as Viewed by the Educational Supervisors. Unpublished MA Thesis, Riyadh: Arab Orient Colleges for Higher Studies.

Al-Sairafi, M. (2009). Administrative Training: Defining the Training Needs and Designing the Training Programs. Cairo: Dar Al-Manahej for Publication and Distribution.

Al-Sakarneh, B. (2009). Administrative Training. Amman: Dar Wa'el for Publication and Distribution.

Al-Salami, F. N. (2012). Creative Leadership and Its Relationship with the Organizational Atmosphere in the Intermediate Public Schools, Jeddah City. MA Thesis, Mecca: Faculty of Education, Umm Al-Qura University.

Al-Shar'ah, A. M. (2011). Training Strategy and Its Effect on the Performance of the Workers in the Public Joint-Stock Companies. Dar Jaless Al-Zaman for Publication and Distribution.

Al-Ta'ani, H. (2007). Contemporary Administrative Training. Amman: Dar Al-Yazouri for Publication and Distribution. Aqeeli, O. (2009). Modern Management of the Human Resources. Amman: Dar Wa'el Publication and Distribution. 
Barnett, A. (2005). The Impact of Transformational Leadership Style of the School Principal on School Learning Environment and Selected Teachers Outcomes. Ph.D. Dissertation. Sydney: University of New South Wales.

Chang, N.,Quang, T. (2011). The Impact of Training on Firm Performance in a Transitional Economy: Evidence from Vietnam. Research and Practice in Human Resource Management, 19, 11-26.

Falola, H., Osibanjo, A., \& Ojo, S. (2014). Effectiveness of Training and Development on Employees’ Performance and Organization Competitiveness in the Nigerian Banking Industry. Bulletin of the Transilvania University of Brasov, 7, 161172.

Jadallah, F. S. (2010). Training Needs of the Basic Stage Teachers in the Public School in Gaza Government. MA Thesis, Cairo: Al-Azhar University.

Jones, M., Jones, R., Latreille, P., \& Sloane, P. (2009). Training, Job Satisfaction, and Work Place Performance in Britain: Evidence for WERS 2004. Labour, 23, 139-157.

Khattak, A., Rehman, S., \& Abdul Rehman, C. (2014). Organizational Success through Corporate Training: A Case Study of Hotel Industry of Pakistan. Journal of Business Studies Quarterly, 6, 167-187.

Manasa, K., \& Reddy, N. (2009). Role of Training in Improving Performance. The IUP Journal of Soft Skills, 3, 72-80.

Mi'mar, S. (2010). Training: Bases and Principles. Jordan: Debono for Printing, Publication and Distribution.

Mkhaimer, A. (2000). Measuring the Institutional Performance of the Governmental Systems. Arab Organization for Administrative Development: Seminars and Conferences, Cairo Arab Republic of Egypt.

Reda, H. (2010). Administrative Training and Qualification. Amman: Dar Al-Rayah for Publication and Distribution.

Salameh, Y. K. (2003). School Modern Management: Its Skill and Criteria (1st ed.). Amman: Dar A'alam Al-Thaqafah. 